\title{
Avaliação da cinética de secagem e atividade antimicrobiana do óleo essencial e hidrolato da parte aérea da Panc Stachys byzantina
}

\author{
Evaluation of the drying kinetic and antimicrobial activity of the essential oil and hydrolate of the \\ aerial part of the Panc Stachys byzantina \\ Evaluación de la actividad cinética y antimicrobiana de secado del aceite esencial y hidrolato de la \\ parte aérea del Panc Stachys byzantina
}

\section{Resumo}

Stachys byzantina K. Koch, conhecida no Brasil como "peixinho da horta ou pulmonária", pertence à família Lamiaceae, é uma planta alimentícia não convencional (Panc). Relatos demonstram que essa planta possui diferentes atividades biológicas como ação antioxidante, anti-inflamatória e inibição microbiológica. Devido as atividades biológicas e a importância em resgatar espécies de Panc, capazes de apresentar diferentes aplicações seja na forma in natura, desidratada ou por meio da extração de óleos voláteis que possuem grande potencial de utilização na indústria. Neste trabalho foi determinada a cinética de secagem e atividade antimicrobiana do óleo essencial e do hidrolato, obtidos por meio dos métodos de hidrodestilação e arraste a vapor. Para a cinética de secagem, o modelo matemático de melhor ajuste foi o logarítmico, com valor de coeficiente de determinação 0,9995 e Qui-quadrado 0,0007. A atividade antimicrobiana foi realizada pelo teste de disco difusão frente as bactérias Bacillus cereus, Listeria monocytogenes, Staphylococcus aureus, Escherichia coli e Salmonella gallinarium. Foi possível observar atividade antibacteriana frente a L. monocytogenes tanto para o óleo essencial (halo $0,9 \mathrm{~cm}$ ), quanto para o hidrolato (halo 1,0 $\mathrm{cm}$ ), ambos obtidos por arraste a vapor utilizando folhas secas à temperatura de $80{ }^{\circ} \mathrm{C}$. Na literatura consultada, não foram encontrados relatos sobre atividade antibacteriana do óleo essencial e/ou hidrolato dessa Panc contra a bactéria L. monocytogenes. Dessa forma, tais resultados podem nortear trabalhos futuros com a aplicação desse material vegetal como composto antimicrobiano, uma vez que a L. monocytogenes é um contaminante patogênico em linhas de produção em indústrias de alimentos. 
Palavras-chave: Modelagem matemática; Hidrodestilação; Arraste a vapor; Listeria monocytogenes; Produtos naturais.

\begin{abstract}
Stachys byzantina K. Koch, known in Brazil as "fish from the garden or pulmonary", belongs to the Lamiaceae family, and is an unconventional food plant (Ufp). Reports show that this plant has different biological activities such as antioxidant, anti-inflammatory and microbiological inhibition. Due to its biological activities and the importance of rescuing species of Ufp, capable of presenting different applications, whether in natura, dehydrated form or through the extraction of volatile oils, which have great potential for use in industry. In this work, the drying kinetics and antimicrobial activity of essential oil and hydrolate, obtained by means of hydrodistillation and steam drag methods, were determined. For drying kinetics, the best fit mathematical model was the logarithmic one, with a coefficient of determination of 0.9995 and Chi-square 0.0007. Antimicrobial activity was performed by disk diffusion test against Bacillus cereus, Listeria monocytogenes, Staphylococcus aureus, Escherichia coli and Salmonella gallinarium bacteria. It was possible to observe antibacterial activity against L. monocytogenes for both the essential oil $(0.9 \mathrm{~cm}$ halo) and the hydrolate $\left(1.0 \mathrm{~cm}\right.$ halo), both obtained by steam drag using dry leaves at a temperature of $80{ }^{\circ} \mathrm{C}$. In the consulted literature, no reports were found on the antibacterial activity of the essential oil and/or hydrolate of this Ufp against L. monocytogenes bacteria. Thus, these results may guide future work with the application of this plant material as an antimicrobial compound, since L. monocytogenes is a pathogenic contaminant in production lines in food industries.
\end{abstract}

Keywords: Mathematical modelling; Hidrodistillation; Steam drag; Listeria monocytogenes; Natural products.

\title{
Resumen
}

Stachys byzantina K. Koch, conocida en Brasil como "pescado del huerto o pulmonar", pertenece a la familia Lamiaceae y es una planta alimenticia no convencional (Panc). Los informes muestran que esta planta tiene diferentes actividades biológicas como la inhibición antioxidante, antiinflamatoria y microbiológica. Por sus actividades biológicas y la importancia de rescatar especies de Panc, capaces de presentar diferentes aplicaciones, ya sea in natura, en forma deshidratada o mediante la extracción de aceites volátiles, los cuales tienen un gran potencial de uso en la industria. En este trabajo se determinó la cinética de secado y la actividad antimicrobiana del aceite esencial y el hidrolato, obtenidos mediante métodos de hidrodestilación y arrastre de vapor. Para la cinética de secado, el modelo matemático de mejor ajuste fue el logarítmico, con un coeficiente de determinación de 0.9995 y Chi-cuadrado 0.0007. La actividad antimicrobiana se realizó mediante una prueba de difusión en disco contra las bacterias Bacillus cereus, Listeria monocytogenes, Staphylococcus aureus, Escherichia coli y Salmonella gallinarium. Se pudo observar actividad antibacteriana contra L. monocytogenes tanto para el aceite esencial (halo de $0,9 \mathrm{~cm}$ ) como para el hidrolato (halo de 1,0 cm), ambos obtenidos por arrastre de vapor utilizando hojas secas a una temperatura de $80^{\circ} \mathrm{C}$. En la literatura consultada no se encontraron reportes sobre la actividad antibacteriana del aceite esencial y / o hidrolato de este Panc contra la bacteria L. monocytogenes. Así, estos resultados pueden orientar el trabajo futuro con la aplicación de este material vegetal como compuesto antimicrobiano, ya que L. monocytogenes es un contaminante patógeno en las líneas de producción de las industrias alimentarias.

Palabras clave: Modelo matemático; Hidrodestilación; Arrastre de vapor; Listeria monocytogenes; Productos naturales.

\section{Introdução}

De modo geral, os produtos naturais são utilizados desde sempre pela humanidade, sendo na forma de alimentos ou como medicamentos (Barreiro et al., 2006). A natureza é a responsável pela produção da maioria das substâncias orgânicas conhecidas, sendo importante ressaltar que o reino vegetal possui responsabilidade pela maior parcela da diversidade química conhecida e registrada na literatura (Montanari \& Bolzani, 2001).

Além dos estudos de produtos naturais, têm atraído a atenção dos pesquisadores, as plantas alimentícias não convencionais (Pancs), com potencial alimentício e desenvolvimento espontâneo, assim denominadas, em função de não serem consumidas em larga escala, ou terem sido muito utilizadas em alguma região, até mesmo na medicina popular, mas que foram gradativamente "esquecidas".

O gênero Stachys é um dos maiores da família Lamiaceae e está vastamente distribuído na Europa e no Leste Asiático, bem como na América (Goren, 2014), onde é consumido em chás de ervas aromáticas (Bahadoria et al. 2020a). A S. byzantina 
tem crescente aplicação na alimentação humana devido ao seu potencial nutricional (Botrel et al., 2020; Silva et al. 2021), fonte de fibras, proteínas, carboidratos, potássio e ferro (Azevedo, 2018). Muitos estudos têm demonstrado que essa planta possui diferentes atividades biológicas como ação antioxidante (Erdemoglu et al., 2006, Bahadori et al., 2020b), ação antiinflamatória (Khanavi et al., 2005), inibição microbiológica de E. coli (Duarte et al., 2007) e B. cereus, Klebsiella pneumoniae, Salmonella typhi e S. aureus (Azevedo, 2018) e potencial atividade anti-Alzheimer, anti-diabética e anti-obesidade (Bahadori et al., 2020a).

Devido ao alto teor de umidade, alimentos de origem vegetal são bastante susceptíveis a deterioração. Dessa forma, a utilização da secagem vem sendo cada vez mais difundida, pois além de oferecer um produto de boa qualidade, permite que seu armazenamento seja por um período mais longo. Existe ainda, a facilidade de redução de massa e volume ao ser transportado (Andrade et al., 2006; Corrêa et al., 2008). Neste sentido, a cinética e a modelagem matemática da secagem são consideradas ferramentas importantes na otimização do processo de secagem (Leite et al., 2015).

Avaliando pesquisas já existentes sobre resultados apresentados por essa planta, e também em função de apresentar diferentes aplicações na forma in natura, para alimentação, e depois de seca, para chás e medicamentos, bem como o óleo essencial para aplicações industriais, este trabalho propõe o estudo das partes aéreas (folhas e galhos) da panc S. byzantina através da cinética de secagem utilizando temperaturas de 40,60 e $80^{\circ} \mathrm{C}$.

\section{Metodologia}

Este trabalho é um estudo experimental, em função da demanda crescente de utilização de produtos naturais biodegradáveis visando sua aplicação futura na indústria. Trabalhos como de Duarte et al. (2007), Morteza-Semnani et al. (2008) Azevedo (2018) e Yousefbeyk et al. (2021), apresentam resultados satisfatórios quando avaliado sua função antimicrobiana. O conhecimento químico e biológico dessa espécie é de extrema importância, pois possibilita a avaliação da viabilidade de aplicação industrial em função da análise de custos versus benefícios. Neste sentido, foi realizada a obtenção do óleo essencial (metabólitos secundários voláteis) e hidrolato pelos métodos de hidrodestilação e arraste a vapor, cuja atividade inibitória, utilizando o método de disco-difusão, foi avaliada frente a cinco cepas bacterianas.

\subsection{Obtenção do material botânico}

A planta S. byzantina foi coletada na área experimental do curso de Agronomia da Universidade Tecnológica Federal

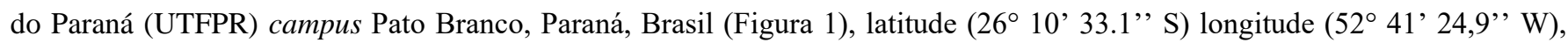
acondicionadas em embalagens plásticas e mantidas refrigeradas até a secagem, conforme apresentado nos itens 2.1.1 e 2.1.2. A nomenclatura e a identificação botânica foram realizadas no laboratório de Botânica e Paisagismo (UTFPR-PB) a partir do material vegetal coletado para avaliação (folhas, caule e raiz). 
Figura 1. Local de coleta da S. byzantina na área experimental do curso de Agronomia da Universidade Tecnológica Federal do Paraná campus Pato Branco.

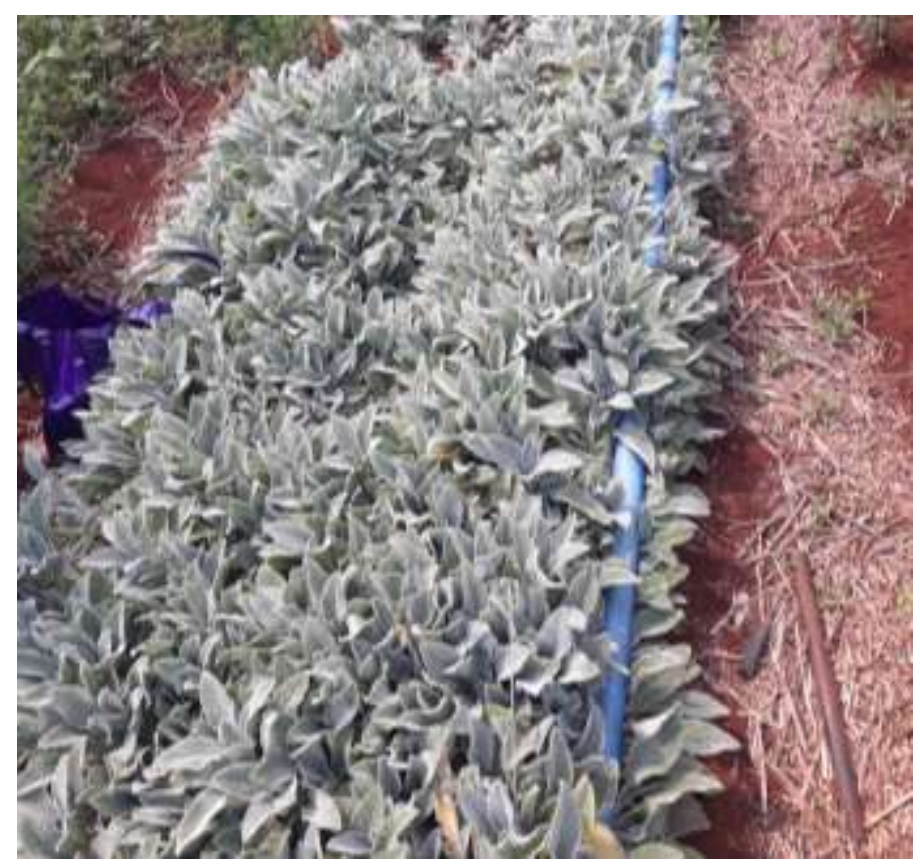

Fonte: Autores (2021).

\subsubsection{Determinação de umidade}

Para este estudo fez-se inicialmente a determinação de umidade das folhas coletadas, baseada em metodologia do Instituto Adolfo Lutz (2008). A secagem foi feita em estufa de circulação de ar a $105{ }^{\circ} \mathrm{C}$ por um período de 3 horas, e após esse período o material foi colocado em dessecador até atingir temperatura ambiente, pesado em balança semi-analítica e retornado para a estufa até atingir massa constante. A determinação de umidade foi calculada por meio da seguinte fórmula:

$$
\% \text { de umidade }=\frac{100 \times \mathbb{N}}{p} \quad \text { Equação (1) }
$$

Onde,

$\mathrm{N}=$ massa em gramas de umidade (perda da massa em $\mathrm{g}$ ).

$\mathrm{P}=$ massa em gramas da amostra.

\subsubsection{Cinética de secagem}

Para o levantamento dos dados cinéticos necessários no estudo da secagem das folhas, foi utilizada estufa com circulação de ar forçado chamada como desidratador PE14 Junior (Pardal), nas temperaturas de 40, 60 e $80{ }^{\circ} \mathrm{C}$ com medições de massa, iniciando a cada 5 minutos, com aumento de tempo em intervalos gradativos até atingir massa constante. Os experimentos foram realizados em triplicata. Com os dados experimentais foram construídas as curvas de secagem utilizando os modelos matemáticos apresentados na Tabela 1, no programa computacional STATISTICA 8.0®, realizando-se análise de regressão não linear, pelo método Quasi-Newton. O grau de ajuste do modelo aos dados experimentais foi avaliado em função da magnitude do Coeficiente de Determinação ajustado $\left(\mathrm{R}^{2}\right)$ e o Qui-Quadrado $\left(\chi^{2}\right)$.

Esse estudo foi importante para avaliar se havia diferença significativa em termos quantitativos de compostos extraídos na obtenção do óleo essencial para cada temperatura. 
Tabela 1. Modelos matemáticos para cinética de secagem.

\begin{tabular}{cc}
\hline MODELO & EQUAÇÃO \\
\hline Logarítmico & $\mathrm{RU}=\mathrm{A} \exp ^{(-\mathrm{kt})+\mathrm{b}}$ \\
Lewis & $\mathrm{RU}=\exp ^{(-\mathrm{kt})}$ \\
\hline
\end{tabular}

Legenda: RU, k, A e b são constantes dos modelos e t é o tempo de secagem (s). Fonte: Autores (2021).

\subsection{Obtenção do óleo essencial das folhas de s. Byzantina}

Para obtenção do óleo essencial foram utilizadas duas técnicas, a primeira com aproximadamente $26 \mathrm{~g}$ do material já seco nas temperaturas de 40,60 e $80{ }^{\circ} \mathrm{C}$ em $1000 \mathrm{~mL}$ de água à temperatura de $100{ }^{\circ} \mathrm{C} \pm 2{ }^{\circ} \mathrm{C}$ por um período de 4 horas, em triplicata, através do método de hidrodestilação, onde a planta permaneceu em contato com a água fervente, podendo estar completamente imersa ou flutuando (Busato et al., 2014) (Koch, Leitzke, Monzani, 2014) e a segunda, por meio do método de destilação por arraste a vapor com aproximadamente $225 \mathrm{~g}$ do material já seco em temperatura de $80{ }^{\circ} \mathrm{C}$, onde a planta entra em contato apenas com o vapor produzido pela água aquecida. Este vapor percorre uma serpentina de cobre, que possibilita a condensação, sendo coletado então, em funil de decantação.

\subsection{Determinação da atividade antimicrobiana}

As amostras obtidas a partir dos experimentos de hidrodestilação e arraste a vapor (óleo essencial e hidrolato), foram submetidas às análises antimicrobianas frente aos microrganismos B. cereus ATCC 10876, L. monocytogenes ATCC 19111, S. aureus ATCC 25923, E. coli ATCC 25922 e S. gallinarium ATCC 9184.

\subsubsection{Métodos de disco-difusão}

Os testes com o método de difusão em ágar foram baseados na metodologia descrita por Savi (2018) e Kashanaki et al. (2010), com adaptações.

As bactérias foram cultivadas em ágar Müller Hinton e incubadas por um período de 24 horas em temperatura entre 35 e $37^{\circ} \mathrm{C}$, a fim de se obter culturas ativas. Após a reativação, as cepas foram padronizadas em escala McFarland 0,5 $\pm 1,5 \mathrm{X}$ $10^{8} \mathrm{UFC}^{-1}$ ). Em seguida, com auxílio de swabs esterilizados a suspensão microbiana foi inoculada em placa de Petri contendo ágar Müller Hinton. Na sequência, o material a ser testado foi impregnado em discos de papel de $5 \mathrm{~mm}$ de diâmetro, os quais foram colocados sobre o meio de cultura inoculado com os microrganismos de interesse, de forma a avaliar se o material testado teve efeito inibitório sobre o microrganismo.

Como controle positivo, foi utilizado o antibiótico tetraciclina em concentração de $1 \mathrm{mg} \mathrm{mL}^{-1}$ e a água peptonada $0,1 \%$ foi avaliada como controle negativo. Para os testes iniciais com o hidrolato, os antimicrobianos padrões, cloreto de benzalcônio $80 \%$ e polihexametileno biguanida $20 \%$ também foram utilizados como controle positivo. As placas foram incubadas em estufa microbiológica por $24 \mathrm{~h}$, à temperatura de $35-37^{\circ} \mathrm{C}$. Após este período, foi realizada a medição do raio dos halos de inibição com régua e os resultados expressos em $\mathrm{cm}$.

\section{Resultados e Discussão}

\subsection{Coleta, identificação e herborização de material botânico}

Foram coletadas amostras de espécime preferencialmente fértil, com órgãos essenciais à classificação do vegetal. A exsicata encontra-se depositada no Herbário da Instituição sob o número de registro HPB 1253 Stachys byzantina K. Koch. 
A coleta foi realizada no período da tarde, em outubro (primavera) de 2020 , com temperaturas entre 16 e $27{ }^{\circ} \mathrm{C}$. As folhas coletadas foram selecionadas e encaminhadas para os testes apresentados nos itens 3.2, 3.3 e 3.4.

\subsection{Secagem}

\subsubsection{Determinação de umidade}

O resultado obtido para o teor de umidade das folhas frescas de $S$. byzantina foi de $74,47 \% \pm 2,35 \%$, o que traz suculência às folhas e contribui positivamente para as suas propriedades sensoriais, porém, por apresentarem elevado conteúdo de umidade, as plantas se deterioram após um curto período de tempo pós colheita, devendo ser consumidas ou processadas rapidamente, a fim de evitar a decomposição de compostos de interesse ou até mesmo redução de produção. Resultados semelhantes foram obtidos por Azevedo (2018) e Botrel et al. (2020) com teores de umidade de 78,22\% e 75,33\% respectivamente.

\subsubsection{Cinética de secagem}

Os parâmetros obtidos na generalização das curvas de secagem para os modelos em estudo são apresentados na Tabela 2.

Tabela 2. Média dos resultados apresentados, utilizando-se dos modelos matemáticos logarítmico e de Lewis, para cinética de secagem das folhas de S. byzantina. - k, a e b são constantes dos modelos; t é o tempo de secagem.

\begin{tabular}{|c|c|c|c|c|c|c|c|c|}
\hline \multirow[t]{2}{*}{ TEMPERATURA } & \multicolumn{5}{|c|}{$\begin{array}{l}\text { MODELO LOGARÍTIMO } \\
\text { RU }=\mathbf{A} \mathbf{E X P}^{(-\mathbf{K T})+\mathbf{B}}\end{array}$} & \multicolumn{3}{|c|}{$\begin{array}{l}\text { MODELO LEWIS } \\
\text { RU }=\mathbf{E X P}^{(-\mathbf{K T})}\end{array}$} \\
\hline & $\mathbf{a}$ & $\mathbf{K}$ & b & $\mathbf{R}^{2}$ & $x^{2}$ & $\mathbf{K}$ & $\mathbf{R}^{2}$ & $x^{2}$ \\
\hline $40{ }^{\circ} \mathrm{C}$ & 0,8747 & 0,0105 & 0,0584 & 0,9940 & 0,0147 & 0,0096 & 0,9863 & 0,0421 \\
\hline $60{ }^{\circ} \mathrm{C}$ & 0,9882 & 0,0338 & 0,0167 & 0,9985 & 0,0028 & 0,0346 & 0,9982 & 0,0034 \\
\hline $80{ }^{\circ} \mathrm{C}$ & 1,0266 & 0,0602 & 0,0272 & 0,9995 & 0,0007 & 0,0637 & 0,9989 & 0,0015 \\
\hline
\end{tabular}

Fonte: Autores (2021).

Verifica-se que os modelos logarítmico e de Lewis resultaram em bons ajustes aos dados experimentais das secagens da S. byzantina. Dentre os modelos testados, o melhor ajuste em todas as temperaturas foi com o modelo logarítmico, em razão de ter apresentado o maior coeficiente de determinação $\left(\mathrm{R}^{2}\right)$ e o menor Qui-Quadrado $\left(\chi^{2}\right)$, segundo Karizaki (2016), porém ambos podem ser utilizados para representar a cinética de secagem, uma vez que ambos tiveram bons ajustes aos dados experimentais.

Observa-se que o aumento da temperatura promoveu um aumento na constante da taxa de secagem $\mathrm{k}$ dos modelos matemáticos. Corrêa et al. (2010) afirmaram que o parâmetro k tende a aumentar com o aumento da temperatura de secagem, pois maiores temperaturas acarretam em maiores taxas de secagem, atingindo o teor de umidade de equilíbrio em menor tempo de submissão do produto ao ar de secagem. Esta constante está relacionada à difusividade térmica no processo de secagem e seu comportamento ganha sentido, pois o aumento da temperatura fornece maior quantidade de energia na forma de calor, o que faz com que a amostra se ajuste mais rapidamente à temperatura em seu entorno, atingindo o teor de água de equilíbrio em menor tempo do que no uso de temperaturas mais baixas. Ainda segundo Babalis e Belessiotis (2004), a constante de secagem "k" pode ser utilizada como uma aproximação para caracterizar o efeito da temperatura e está relacionada à difusividade 
efetiva no processo de secagem no período decrescente e à difusão líquida que controla o processo. Comportamento semelhante foi verificado por Alves et al. (2017), ao trabalharem com a cinética de secagem de Hyptis suaveolens (L.) também pertencente à família Lamiaceae e por Alves et al. (2016) na cinética de secagem da polpa de manga.

Quanto ao parâmetro a, verificou-se que houve aumento ao elevar a temperatura de secagem, que pode também ser observado comportamento semelhante citado por Martinazzo et al. (2007), em cujo trabalho utilizaram capim-limão e Silva et al. (2019) o mandacaru, por outro lado, em relação ao parâmetro b, não teve comportamento de aumento ou redução com aumento da temperatura.

Ao analisar as Figuras 2 e 3, observa-se que as curvas de secagem foram influenciadas pela temperatura, sendo observada redução gradativa nos tempos de secagem à medida que a temperatura do ar de secagem foi aumentada. A amostra levou 360 min para atingir a umidade de equilíbrio a $40{ }^{\circ} \mathrm{C}$, enquanto que na temperatura de $60{ }^{\circ} \mathrm{C}$, o tempo de secagem foi de $105 \mathrm{~min}$ e a $80{ }^{\circ} \mathrm{C}$ o tempo de secagem foi de $50 \mathrm{~min}$.

Este comportamento é frequente e pode ser observado em estudos distintos como o de Fogaça et al. (2021), que investigaram a cinética de secagem de folhas de Phormium tenax em temperaturas de 70 , 90 e $100{ }^{\circ} \mathrm{C}$, para determinação de sua difusividade efetiva, energia de ativação e ajustes de modelos matemáticos aos dados experimentais, Souza et al. (2021) também estudaram a secagem do epicarpo (casca), mesocarpo (polpa) e endocarpo (amêndoa) do tucumã nas temperaturas de 60,70 e $80^{\circ} \mathrm{C}$, neste trabalho observou-se que o aumento da temperatura reduziu o tempo de queda da razão de umidade de ambas as partes da planta estudada. Isso ocorre, em razão da maior taxa de remoção de água do produto devido a um maior gradiente de umidade entre o produto e o ar, ocasionado pelo aumento da temperatura (Sousa et al., 2011).

Figura 3. Cinética de secagem utilizando modelo

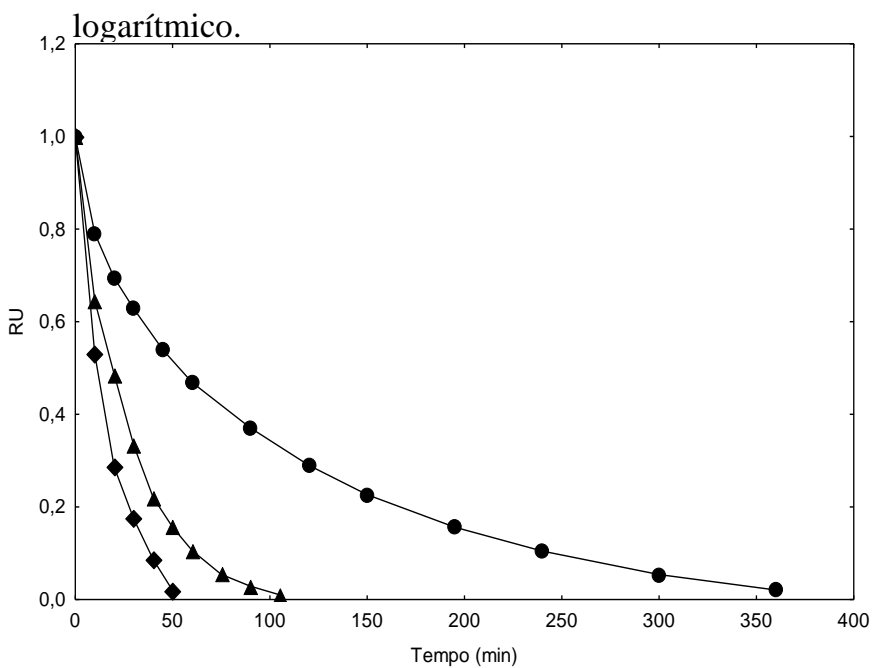

Legenda: $\bullet$ Temperatura de secagem a $40{ }^{\circ} \mathrm{C}-\boldsymbol{\Delta}$ Temperatura de secagem a 60 Legenda: $\bullet$ Temperatura de secagem a $40{ }^{\circ} \mathrm{C}-\boldsymbol{\Delta}$ Temperatura de secagem a 60 ${ }^{\circ} \mathrm{C}$ - Temperatura de secagem a $80^{\circ} \mathrm{C}$. Fonte: Autores (2021)

Figura 3. Cinética de secagem utilizando modelo de Lewis.

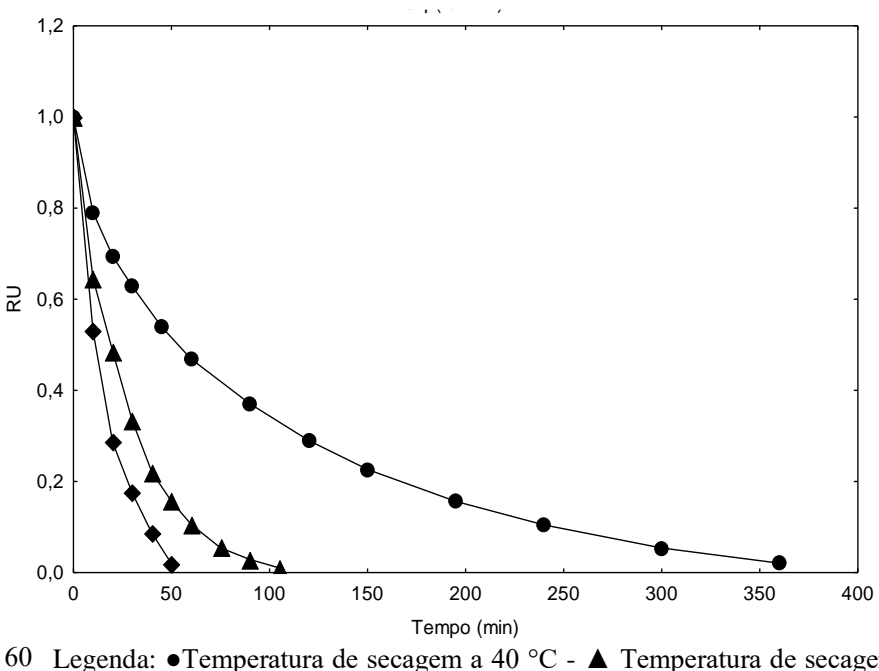

${ }^{\circ} \mathrm{C}$ - $\downarrow$ Temperatura de secagem a $80{ }^{\circ} \mathrm{C}$. Fonte: Autores (2021)

\subsection{Obtenção do óleo essencial das folhas de s. Byzantina}

Em estudo realizado por Júnior et al. (2020) para verificar as alterações físico-químicas e biológicas dos óleos essenciais das folhas de Alpinia zerumbet, a partir de diferentes temperaturas de secagem, concluiu-se que a temperatura indicada para a espécie é a de $45^{\circ} \mathrm{C}$, pois a mesma apresentou melhor rendimento, melhor atividade bactericida e atoxicidade do óleo essencial obtido. Outro estudo, realizado por Borges et al. (2019) indicou que a temperatura de $55{ }^{\circ} \mathrm{C}$ proporciona maior rendimento de óleo essencial de capim-limão (Cymbopogon citratus (D.C.) Stapf). 
Porém, para este estudo, utilizou-se $80{ }^{\circ} \mathrm{C}$ como temperatura de secagem do material vegetal, pois essa temperatura apresentou o melhor rendimento de obtenção de óleo essencial através do método de hidrodestilação $(0,7 \%)$.

O óleo essencial, bem como o hidrolato obtidos por hidrodestilação e por arraste a vapor, foram submetidos à análise antimicrobiana apresentada no item 3.4 .

\subsection{Atividade antimicrobiana}

A atividade antimicrobiana das amostras de hidrolato, óleo essencial, cloreto de benzalcônio $80 \%$ e polihexametileno biguanida $20 \%$ foram testadas pelo método de disco difusão frente as bactérias B. cereus ATCC 10876, L. monocytogenes ATCC 19111, S. aureus ATCC 25923, E. coli ATCC 25922 e S. gallinarium ATCC 9184.

Porém, apenas o cloreto de benzalcônio $80 \%$ e o poliexametileno biguanida $20 \%$ que são agentes antimicrobianos utilizados em indústrias de domissanitários, apresentaram inibição para todas as bactérias testadas, com exceção de $S$. aureus que apresentou contaminação durante a realização da análise conforme descrito na Tabela 3.

As análises realizadas com o óleo essencial e o hidrolato obtidos por meio da hidrodestilação não apresentaram inibição de nenhum dos microrganismos avaliados, porém, o óleo essencial e o hidrolato obtidos pelo método de arraste a vapor, apresentaram inibição para a bactéria L. monocytogenes, onde foram verificados halos de 0,9 e 1,0 cm, para o óleo essencial e o hidrolato, respectivamente, conforme resultados apresentados na Tabela 3.

Tabela 3. Resultados expressos em cm para leitura do halo de inibição - (**) microrganismo não cresceu na placa, (-) amostras contaminadas, (X) sem inibição, (C+) Controle positivo/tetraciclina $1 \mathrm{mg} \mathrm{mL}^{-1}$, (C) Controle negativo / água peptonada $0,1 \%$, (H.60) Hidrolato $60{ }^{\circ} \mathrm{C}$ (P.60.1), (H.40) Hidrolato $40{ }^{\circ} \mathrm{C}$ (P.40.1.1), (H.80) Hidrolato $80{ }^{\circ} \mathrm{C}$ (P.80.1), (C.B.80) cloreto de benzalcônio 80\%, (P.B.20) polihexametileno biguanida 20\%, (O.E.80) Óleo Essencial extração arraste a vapor $80^{\circ} \mathrm{C},($ H.80.2) Hidrolato extração arraste a vapor $80^{\circ} \mathrm{C}$.

\begin{tabular}{|c|c|c|c|c|c|c|c|c|c|}
\hline $\begin{array}{ll}\text { MICRORGANISMOS } & \text { AGENTES DE TESTE } \\
\end{array}$ & $\mathrm{C}+$ & C- & H.60 & H.40 & H.80 & C.B.80 & P.B.20 & O.E.80 & H.80.2 \\
\hline S. aureus. - ATCC 25923 & $2,8 \mathrm{~cm}$ & $\mathrm{X}$ & $\mathrm{X}$ & $\mathrm{X}$ & $\mathrm{X}$ & - & - & $\mathrm{X}$ & $\mathrm{X}$ \\
\hline B. cereus - ATCC 10876 & $1,3 \mathrm{~cm}$ & $\mathrm{x}$ & $\mathrm{x}$ & $\mathrm{X}$ & $\mathrm{X}$ & $2,8 \mathrm{~cm}$ & $2,2 \mathrm{~cm}$ & $\mathrm{x}$ & $\mathrm{x}$ \\
\hline L. monocytogenes - ATCC 19111 & $2,7 \mathrm{~cm}$ & $\mathrm{x}$ & $\mathrm{x}$ & $\mathrm{x}$ & $\mathrm{x}$ & $3,9 \mathrm{~cm}$ & $3,0 \mathrm{~cm}$ & $0,9 \mathrm{~cm}$ & $1,0 \mathrm{~cm}$ \\
\hline E. coli-ATCC 25922 & $1,1 \mathrm{~cm}$ & $\mathrm{x}$ & $\mathrm{x}$ & $\mathrm{x}$ & $\mathrm{x}$ & $2,5 \mathrm{~cm}$ & $2,2 \mathrm{~cm}$ & ** & ** \\
\hline S. gallinarium - ATCC 9184 & $3,1 \mathrm{~cm}$ & $\mathrm{x}$ & $\mathrm{x}$ & $\mathrm{X}$ & $\mathrm{X}$ & $3,6 \mathrm{~cm}$ & $2,6 \mathrm{~cm}$ & $\mathrm{x}$ & $\mathrm{x}$ \\
\hline
\end{tabular}

Fonte: Autores (2021).

Apesar de neste estudo, o óleo essencial e/ou hidrolato não apresentarem inibição para os microrganismos B. cereus ATCC 10876, , S. aureus ATCC 25923, E. coli ATCC 25922 e S. gallinarium ATCC 9184, um estudo realizado, utilizando diferentes espécies do gênero Stachys, relata que seus extratos metanólicos, possuem potencial inibição para $S$. aureus PTCC 1112, Streptococcus sanguis PTCC 1449, E. coli PTCC 1330, Pseudomonas aeruginosa PTCC 1074 e Klebsiella pneumoniae PTCC 1053, (Morteza-Semnani et al., 2008). Outro estudo efetuado por Yousefbeyk et al. (2021), realizou a caracterização, avaliou atividade antioxidante, antibacteriana e citotóxica, para o extrato de $S$. byzantina $\mathrm{K}$. Koch, apresentando resultado de inibição para E. coli (ATCC 8739).

Ao avaliar os dados apresentados na Tabela 3 e demonstrados na Figura 4, a inibição obtida para as amostras C.B.80 (Figura 4 - A, B, C e D) e do P.B.20 (Figura 4 -E, F, G e H) que são antimicrobianos industriais comparando-os com os 
resultados de O.E.80 (Figura 4 - J) e H.80.2 (Figura 4 - I) podem ser utilizados como base para estudos futuros de diferentes proporções entre inibidores industriais, óleo essencial e hidrolato, a fim de potencializar seu uso e agregar valor ao óleo essencial e hidrolato obtidos de S. byzantina K. Koch. Essa potencialidade fica evidenciada principalmente quando se considera a inibição frente a L. monocytogenes que, segundo Mahoney et al. (2022), é uma ameaça ao sistema alimentar, sendo considerada responsável por vários surtos de contaminação de origem alimentar em todo o mundo.

Figura 4. Imagens dos resultados da análise microbiológica. - A (cloreto de benzalcônio 80\% /E. coli), B (cloreto de benzalcônio $80 \%$ / S. gallinarum), C (cloreto de benzalcônio 80\% / B. Cereus), D (cloreto de benzalcônio $80 \%$ / L. monocytogenes, E (poliexametileno biguanida 20\% / L. monocytogenes), F (poliexametileno biguanida 20\% / S. gallinarum), $\mathrm{G}$ (poliexametileno biguanida $20 \%$ / B. Cereus), H (poliexametileno biguanida $20 \%$ / E. coli), I ( hidrolato $80{ }^{\circ} \mathrm{C} \mathrm{/} \mathrm{L.}$ monocytogenes), $\mathrm{J}$ (Óleo essencial $80{ }^{\circ} \mathrm{C} /$ L. monocytogenes).
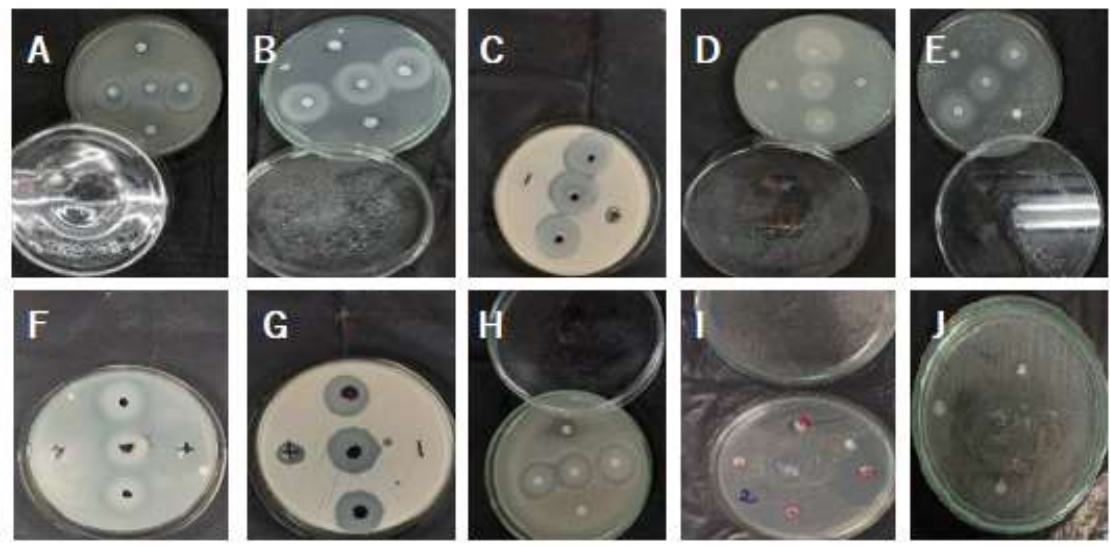

Fonte: Autores (2021).

\section{Conclusão}

Para o processo de secagem, verificou-se que na temperatura de $80{ }^{\circ} \mathrm{C}$ a umidade de equilíbrio foi atingida mais rapidamente com economia de tempo e energia, quando comparada com as demais condições estudadas, sendo esta então, a melhor condição de secagem. As curvas generalizadas de secagem obtidas na faixa de temperatura de 40 a $80{ }^{\circ} \mathrm{C}$ mostraram que o modelo logarítmico apresentou melhor ajuste aos dados experimentais com base nos valores de $\mathrm{R}^{2}$ e do Qui-Quadrado $\left(\chi^{2}\right)$, melhor descrevendo os dados experimentais em todas as condições estudadas.

Este estudo evidenciou que o óleo essencial e hidrolato apresentaram melhores valores, tanto em relação à cinética de secagem como em relação à atividade microbiológica contra a L. monocytogenes, foram obtidos por meio da metodologia de arraste a vapor com as folhas previamente secas à temperatura de $80^{\circ} \mathrm{C}$, o que torna viável sua utilização em escala industrial.

Estudos futuros devem ser realizados a fim de comparar temperaturas mais baixas com o mesmo método de obtenção de óleo essencial, a fim de ampliar a escala de inibição visando sua utilização em indústrias de domissanitários e/ou aplicação em filmes biodegradáveis como composto antimicrobiano natural em alimentos, uma vez que a L. monocytogenes, pode estar presente como microrganismo contaminante de alimentos e, o óleo essencial obtido desta planta apresentou atividade antimicrobiana frente a esse microrganismo.

\section{Referências}

Alves, J. J. L. et al. (2017). Cinética de secagem das folhas de Hyptis suaveolens. Revista Brasileira de Plantas Medicinais, 19(2), 168-176.

Alves, G. S. et al. (2016). Modelagem matemática para descrição da cinética de secagem da polpa da manga cv. Espada. Revista Principia, (31), 9-14. 
Andrade, E. T. et al. (2006). Cinética de secagem e qualidade de sementes de feijão. Engevista, 8(2), 83-95.

Azevedo, T. D. (2018) Propriedades nutricionais, antioxidantes, antimicrobianas e toxicidade preliminar do peixinho da horta (Stachys byzantina K. Koch). Dissertação (mestrado em alimentação e nutrição).

Babalis, S. J., \& Belessiotis, V. G. (2004). Influence of the drying conditions on the drying constants and moisture diffusivity during the thin-layer drying of figs. Journal of Food Engineering, 65(3), 449-458.

Bahadori, M. B. et al. (2020a). Essential oils of hedgenettles (Stachys inflata, S. lavandulifolia, and S. byzantina) have antioxidant, anti-Alzheimer, antidiabetic, and anti-obesity potential: A comparative study. Industrial Crops \& Products, 145(112089), 1-8.

Bahadori, M. B. et al. (2020b). The health benefits of three Hedgenettle herbal teas (Stachys byzantina, Stachys inflata, and Stachys lavandulifolia) profiling phenolic and antioxidant activities. European Journal of Integrative Medicine, 36(101134), 1-7.

Barreiro, E. J; Bolzani, V. S da., \& Viegas, C. Jr. (2006). Os produtos naturais e a química medicinal moderna. Revista Química Nova, $29(2), 326-337$.

Borges, F. F. et al. (2019). Efeito da secagem sobre o rendimento de óleo essencial de capim-limão (Cymbopogon citratus (D.C.) Stapf). Global Science and Technology, 12(3), 01-19.

Botrel, N. et al. (2020). Valor nutricional de hortaliças folhosas não convencionais cultivadas no Bioma Cerrado. Brazilian Journal of Food Technology, 23,17.

Busato, N. V. et al. (2014). Estratégias de modelagem da extração de óleos essenciais por hidrodestilação e destilação a vapor. Revista Ciência Rural, 44(9), 1574-1582.

Corrêa, J. L. G. et al. (2008). Desidratação osmótica de tomate seguida de secagem. Revista Brasileira de Produtos Agroindustriais, 10(1), 35-42.

Corrêa, P. C. et al. (2010). Modelagem matemática e determinação das propriedades termodinâmicas do café (Coffea arabica L.) durante o processo de secagem. Revista Ceres, 57(5), 595-601.

Duarte, C. et al. (2007). Activity of essential oils from Brazilian medicinal plants on Escherichia coli. Journal of Ethnopharmacology, 111, $197-201$.

Erdemoglu. N. et al. (2006). Antioxidant Activities of Some Lamiaceae Plant Extracts. Phytotherapy Research, 20(1), 9-13.

Fogaça, M. B. et al. (2021). Estudo da cinética de secagem de folhas de Phormium tenax para uso em compósitos poliméricos. Revista de Engenharia e Tecnologia, 13(1), 105-114.

Goren, A. C. (2014) Use of Stachys species (Mountain Tea) as herbal tea and food. Records of Natural Products, 8(2), 71-82.

Isntituto Adolfo Lutz. (2008). Métodos físico-químicos para análise de alimentos. http://www.ial.sp.gov.br/resources/editorinplace/ial/2016_3_19/na alisedealimentosial_2008.pdf

Junior, P. S. S. et al. (2020). Alterações físico-químicas e biológicas dos óleos essenciais das folhas Alpinia zerumbet a partir de diferentes temperaturas de secagem. Brazilian Journal of Development, 6(4), 22392-22403.

Kashanaki, R. et al. (2010). Antimicrobial Activity and Volatile Constituents of Essential Oils from Leaf and Stem of Stachys byzantina C.Koch. Revista Jeopb, 13(3), $371-376$.

Karizaki, V. M. (2016). Kinetic modeling and determination of mass transfer parameters during cooking of rice. Innovative Food Science and Emerging Technologies, 38, 131-138.

Khanavi, M. et al. (2005). Phytochemical investigation and anti-inflammatory activity of aerial parts of Stachys byzanthina C. Koch. Journal of Ethnopharmacology, 97(3), 463-468.

Koch, D.; Leitzke, M.; Monzani, R. M. (2014). Extração de óleos essenciais por meio de hidrodestilação para controle de fitopatógenos. VII MICTI - Mostra Nacional de Iniciação Cientifica e Tecnológica Interdisciplinar. IFC - Araquari.

Leite, A. L. M. P. et al. (2015). Contração volumétrica e cinética de secagem de fatias de banana variedade Terra. Pesquisa Agropecuária Tropical, 45(2), $155-162$.

Martinazzo, A. P. et al. (2007). Análise e descrição matemática da cinética de secagem de folhas de capim-limão. Revista Brasileira de Engenharia Agrícola e Ambiental, 11(3), 301-306.

Mahoney, D. B. J. et al (2022). Associations between Listeria monocytogenes genomic characteristics and adhesion to polystyrene at $8{ }^{\circ} \mathrm{C}$. Food Microbiology, 102(103915), 1-9.

Montanari, C. A., \& Bolzani, V. S. (2001). Planejamento racional de fármacos baseado em produtos naturais. Revista Química Nova, 24(1), 105-111.

Morteza-Semnani, K. et al. (2008). Antimicrobial Studies on Extracts of Four Species of Stachys. Indian Journal of Pharmaceutical Sciences, 70(3), 403-406.

Savi, A. (2018) Caracterização química, potencial antimicrobiano e antioxidante de polissacarídeo extraído de cará-moela. Dissertação Mestrado Universidade Tecnológico Federal do Paraná (Programa de Pós-Graduação em Tecnologia de Processos Químicos e Bioquímicos).

Silva, L. F. L. et al. (2021). Nutritional characterisation and grouping of unconventional vegetables in Brazil. The Journal of Horticultural Science and Biotechnology, 96, p. 508-513. 
Research, Society and Development, v. 10, n. 17, e84101724265, 2021

(CC BY 4.0) | ISSN 2525-3409 | DOI: http://dx.doi.org/10.33448/rsd-v10i17.24265

Silva, L. M. Q. de. et al. (2019). Avaliação da cinética de secagem do mandacaru (Cereus jamacaru P.DC.) EM ESTUFA. I Congresso Internacional de Meio Ambiente e Sociedade e III Congresso Internacional de Diversidade de Seminário.

Sousa, K. A. et al. (2011). Cinética de secagem do nabo forrageiro (Raphanus sativus L.). Revista Ciência Agronômica, 42(4), 883-892.

Souza, T. T. C. de.et al. (2021). Modelagem e propriedades termodinâmicas da secagem do epicarpo, mesocarpo e endocarpo do tucumã. Brazilian Journal of Food Technology, 24 (e2020032), 1-13.

Yousefbeyk. F. et al. (2021). Síntese verde de nanopartículas de prata de Stachys byzantina K. Koch: caracterização, atividade antioxidante, antibacteriana e citotóxica, Particulate Science and Technology, 39, 1-14. 